\title{
Parent-Reported Deficits in Executive Function and Sleep-Disordered Breathing in Adolescent Behavioral Weight Loss Program Participants
}

\author{
Jonathan Mietchen $^{1} \cdot$ Shawn D. Gale ${ }^{1,2} \cdot$ Chad D. Jensen $^{1}$ \\ Received: 19 March 2016 /Revised: 23 June 2016 / Accepted: 24 June 2016 / Published online: 11 July 2016 \\ (C) American Academy of Pediatric Neuropsychology 2016
}

\begin{abstract}
Objective Children and adolescents with obesity are at increased risk for developing sleep-disordered breathing (SDB), and SDB has been associated with cognitive deficits including executive dysfunction. The aim of this study was to examine the relationship between executive functioning and SDB among adolescents participating in a behavioral weight loss intervention.

Methods Adolescents $(n=37)$ and their caregivers completed the Behavior Rating Inventory of Executive Function (BRIEF). Sleep was characterized by the Pediatric Sleep Questionnaire (PSQ). The Sleep-Related Breathing Disorder scale on the PSQ was used to classify participants as at risk or not at risk for SDB. The Pediatric Daytime Sleepiness Scale (PDSS) was also administered.

Results Significant correlations were found between SDB and executive functioning $(r=0.75 ; p<0.001)$. Significant differences were observed between adolescents classified as at risk or not at risk for SDB on the BRIEF parent-report form $(F(1$, $35)=3.73 ; p<0.01)$ which represented a large effect size $(d=1.73)$. However, self-ratings on the BRIEF were not different between groups $(F(1,35)=1.24 ; p>0.05)$. The PSQ was predictive of the PDSS as well as the composite BRIEF score while the inhibition scale of the BRIEF predicted weight loss at 1 year.

Conclusions Overweight or obese adolescents participating in a behavioral weight loss program that were at increased risk
\end{abstract}

Shawn D. Gale

shawn_gale@byu.edu

1 Department of Psychology, Brigham Young University, 1001 SWKT, Provo, UT 84602, USA

2 Neuroscience Center, Brigham Young University, Provo, UT, USA for SDB were rated by caregivers as demonstrating clinically significant executive dysfunction. Furthermore, ratings of inhibitory control predicted weight loss at 1 year.

Keywords Sleep $\cdot$ Sleep disordered breathing $\cdot$ Executive function $\cdot$ Cognition $\cdot$ Adolescent $\cdot$ Obesity

Obesity is among the most common pediatric health conditions (Ogden et al. 2014). Although often seen as a disease in its own right, obesity is considered to be a risk factor for the development of other health conditions including sleep-disordered breathing (SDB) which can range from mild snoring to obstructive sleep apnea (OSA; Alonso-Alvarez et al. 2014; Lobstein et al. 2004; Verhulst et al. 2008). SDB has been associated with unfavorable health consequences, such as hypertension and metabolic syndrome (Montesano et al. 2010; Nisbet et al. 2013; Redline et al. 2007). Past research has demonstrated that the risk for developing SDB is two to four times higher in obese children and adolescents compared to their non-obese peers, and up to $39 \%$ of obese children may experience sleepdisordered breathing (Alonso-Alvarez et al. 2014; Lobstein et al. 2004). There is also evidence of an association between Body Mass Index (BMI) and SDB severity, indicating that individuals with severe obesity are at greatest risk for developing SDB (Lobstein et al. 2004; Redline et al. 1999; Verhulst et al. 2008).

In addition to significant health consequences, SDB in children is associated with behavioral difficulties including impairment in cognitive and academic function (Bourke et al. 2011). Numerous studies have demonstrated that individuals with SDB display deficits in executive function. Specifically, deficits have been 
reported in the areas of working memory, planning, organization, inhibition of impulses, attention, and decision making (Engleman et al. 1993, 1997; Hunter et al. 2016; Karpinski et al. 2008; McNally et al. 2012; O'Brien et al. 2004; Pietropaoli et al. 2015; Thomas et al. 2005). These SDB-related cognitive difficulties are likely related to that fact that SDB results in nocturnal arousals which disrupt the sleep stages, resulting in sleep fragmentation (Jones and Harrison 2001). Moreover, SDB has been shown to decrease blood oxygenation resulting in hypoxia (Bass et al. 2004). Both sleep fragmentation and hypoxia can lead to a disruption of neural mechanisms associated with sleep and lead to disruption in the restorative processes of sleep (Beebe and Gozal 2002). Furthermore, Beebe and Gozal (2002) explain how SDB, specifically sleep apnea, affects the prefrontal cortex, resulting in executive dysfunction. Impulsivity and inhibition are among the common symptoms associated with pediatric SDB (Beebe et al. 2004). Functional neuroimaging studies attest to the importance of executive functioning in weight control interventions. For example, one study examined individuals' ability to resist cravings when presented with food stimuli following gastric bypass surgery. When individuals were asked to resist the craving, there appeared to be increased activation in the dorsolateral prefrontal cortex (DLPFC; Goldman et al. 2013). Those participants who were more successful in losing weight showed significantly more activation in the DLPFC when instructed to resist cravings than those participants considered to be less successful (Goldman et al. 2013). The DLPFC is an area that is considered important for executive functioning and as discussed earlier, and Beebe and Gozal (2002) proposed that the prefrontal cortex is affected by SDB (Berman et al. 1995). Thus, given the associations between obesity and SDB, executive function and successful weight loss, and SDB and executive functioning, it may be important to consider these factors in the context of weight control intervention. It is possible that SDB plays an important role in the relationship between executive dysfunction and pediatric obesity, a role that has largely gone uninvestigated.

The aim of the current study was to evaluate whether overweight/obese adolescents participating in a behavioral weight loss program may exhibit symptoms of SDB and whether these symptoms might be associated with self and caregiver-reported executive functioning. We also hoped to determine whether there is a relationship between executive function and weight change over time. We hypothesized that participants at risk for SDB would demonstrate deficits in executive functioning compared to obese adolescents not at risk for SDB and that executive functioning would be associated with weight change over time.

\section{Methods}

\section{Participants}

Thirty-seven adolescents enrolled in a behavioral weight loss intervention program participated in the study. Initially, there were 42 potential participants but we excluded participants who did not complete the study assessment $(n=2)$ or whose executive function profiles were of questionable validity per the manual for the Behavior Rating Inventory of Executive Function ( $n=3$; BRIEF; Gioia et al. 2000). Participant ages ranged from 12 to $17(M=14.32, \mathrm{SD}=1.56)$, and there were 14 male and 23 female participants. All participants had a Body Mass Index (BMI) percentile categorized as overweight (i.e., $\geq 85$ th percentile) or obese (i.e., $\geq 95$ th percentile; $M=97.71$, $\mathrm{SD}=1.66$; Kuczmarski et al. 2002; Ogden et al. 2014). Demographics of the participants are presented in Table 1.

Only English speakers were recruited to participate. The primary caregiver who prepared meals for the adolescent completed the parent-report questionnaires. Adolescents with severe mental illness (including but not limited to bipolar disorder, recent traumatic brain injury, and psychotic disorders) were excluded from the study. The Institutional Review Board of the authors' institution approved all study procedures. Written informed consent was obtained from parents/guardians, and adolescent participants completed written assent.

\section{Measures}

\section{Anthropometric Data}

Height (in inches) and weight (in pounds) were measured at the time of assessment by a trained research assistant using a calibrated electronic scale (Seca 217, SECA Corp., Hanover, MD) and a portable stadiometer (Seca 813, SECA Corp., Hanover, MD). Height and weight were measured without shoes in light clothing. Height, weight, age, and sex data were used to calculate the percent in which each participant was over their ideal BMI. This measure was used because it is sensitive to change and it is robust (Paluch et al. 2007; Pretlow et al. 2015). This data was also used to calculate the Body Mass Index $z$ score (BMIz), a value standardized for age and sex which is robust to restriction of range. BMIz transformations were completed using a SAS application provided by the Centers for Disease Control and Prevention (CDC n.d.). 
Table 1 Demographics of participants

\begin{tabular}{|c|c|c|c|}
\hline & $\begin{array}{l}\text { Total sample } \\
(n=37) \\
\text { Mean (SD) }\end{array}$ & $\begin{array}{l}\text { Low SDB risk } \\
(n=17) \\
\text { Mean (SD) }\end{array}$ & $\begin{array}{l}\text { High SDB risk } \\
(n=20) \\
\text { Mean (SD) }\end{array}$ \\
\hline Age & $14.32(1.56)$ & $14.35(1.73)$ & $14.15(1.35)$ \\
\hline $\mathrm{BMIz}^{\mathrm{a}}$ & $2.13(0.37)$ & $2.14(0.41)$ & $2.12(0.34)$ \\
\hline \multirow[t]{2}{*}{ Percent over BMI } & $76.11(38.59)$ & $74.05(34.39)$ & $77.96(42.87)$ \\
\hline & $N(\%)$ & $N(\%)$ & $N(\%)$ \\
\hline \multicolumn{4}{|l|}{ Sex } \\
\hline Male & $14(37.8)$ & $5(29.4)$ & $9(45.0)$ \\
\hline Female & $23(62.2)$ & $12(70.6)$ & $11(55.0)$ \\
\hline \multicolumn{4}{|l|}{ Educational attainment $^{\mathrm{b}}$} \\
\hline Junior high school (7-9 total years) & $26(70.2)$ & $12(70.5)$ & $14(70)$ \\
\hline High school (10-12 total years) & $10(27)$ & $4(23.6)$ & $6(30)$ \\
\hline \multicolumn{4}{|l|}{ Race/ethnicity ${ }^{\mathrm{b}}$} \\
\hline White & $26(70.3)$ & $12(70.6)$ & $14(70)$ \\
\hline Hispanic/Latino & $6(16.2)$ & $5(29.4)$ & $1(5)$ \\
\hline Black & $0(0)$ & $0(0)$ & $0(0)$ \\
\hline Asian & $0(0)$ & $0(0)$ & $0(0)$ \\
\hline Other & $1(2.7)$ & $0(0)$ & $1(5)$ \\
\hline \multicolumn{4}{|l|}{ Mother's weight ${ }^{\mathrm{b}}$} \\
\hline Underweight or average weight & $6(16.2)$ & $3(17.6)$ & $3(15)$ \\
\hline Slightly or very overweight & $30(81.1)$ & $13(76.4)$ & $17(85)$ \\
\hline \multicolumn{4}{|l|}{ Father's weight ${ }^{\mathrm{b}}$} \\
\hline Underweight or average weight & $0(0)$ & $0(0)$ & $0(0)$ \\
\hline Slightly or very overweight & $27(73.0)$ & $15(88.2)$ & $12(60)$ \\
\hline History of ADHD & $8(22)$ & $2(12)$ & $6(30)$ \\
\hline History of sleep disorders & $4(11)$ & $1(6)$ & $3(15)$ \\
\hline
\end{tabular}

$S D B$ sleep-disordered breathing, $A D H D$ attention-deficit/hyperactivity disorder

${ }^{\text {a }}$ One participant's BMIz was not included because a valid $z$ score could not be obtained due to an extremely high BMI

${ }^{\mathrm{b}}$ Some demographic data is missing. This is due to respondents failing to complete the pre-treatment survey

\section{Sleep-Disordered Breathing}

The adolescents' caregiver completed the Pediatric Sleep Questionnaire (PSQ) in its entirety (Chervin et al. 2000). Adolescents were assessed for risk of SDB using the Sleep-Related Breathing Disorder scale of the PSQ. The Sleep-Related Breathing Disorder subscale on the PSQ consists of 22 items that measure symptoms of SDB including symptoms such as snoring, cessation of breathing during sleep, and excessive daytime sleepiness. This measure has good internal consistency $(\alpha=0.89)$ and good test-retest reliability $(\rho=0.75)$. Sensitivity and specificity of this subscale have been reported as 0.85 and 0.87 , respectively. Scores above 0.33 are considered to be indicative of SDB, as established by receiver operating characteristic (ROC) analyses in past research (Chervin et al. 2000). We also collected information regarding previous diagnoses including attention-deficit/hyperactivity disorder (ADHD) and OSA from the PSQ and also asked if the subjects were currently being treated for these conditions.

\section{Executive Function}

The Behavior Rating Inventory of Executive Function (BRIEF) parent (i.e., caregiver) form was used to measure executive function. This measure consists of 86 items, completed by the parent/caregiver, that are intended to measure various facets of executive function including inhibition, shift, emotional control, initiation, working memory, planning and organizing, material organization, and monitoring (Gioia et al. 2000). The Behavioral Regulation Index consists of three subscales: inhibit, shift, and emotional control. The Behavioral Regulation Index is considered a measure of a child's capacity to engage in socially acceptable behavior via inhibitory control, cognitive shifting, and emotional regulation. The Metacognition Index includes the initiate, working memory, planning and organizing, organization of materials, and 
monitor subscales. The Metacognition Index is intended to measure a child's initiation and successful completion of problem-solving tasks. Finally, the Global Executive Composite incorporates all eight clinical scales. This summary score represents the child's overall executive functioning abilities. The Global Executive Composite has demonstrated high internal consistency $(\alpha=0.97)$ and appears to be a good measure of executive function (Gioia et al. 2000). Subscales and indices on the BRIEF are standardized $T$ scores $(M=50$, $\mathrm{SD}=10$ ) with higher scores reflecting greater impairment, while scores above 65 are considered to be in the clinical range.

The Behavior Rating Inventory of Executive FunctionSelf-Report (BRIEF-SR) is a self-report measure of executive function appropriate for adolescents ages 11-18. The BRIEFSR consists of 80 questions with similar clinical scales and overall indices as mentioned above. The Global Executive Composite on the BRIEF-SR has also demonstrated high internal consistency ( $\alpha=0.96$; Walker and D'Amato 2006).

\section{Pediatric Daytime Sleepiness Scale}

The Pediatric Daytime Sleepiness Scale (PDSS; Drake et al. 2003) is an eight-item questionnaire in which the adolescent responds to questions regarding daytime sleepiness symptoms (e.g., sleepiness at school, difficulty waking in the morning, etc.). An exploratory factor analysis demonstrated that the PDSS consists of a single factor and appears to be a valid measure of daytime sleepiness. The PDSS has a reported Cronbach's alpha of 0.81 , demonstrating good internal consistency and appears to be a reliable measure as well (Drake et al. 2003).

\section{Procedures}

Participating caregivers and adolescents completed the study measures prior to beginning the behavioral weight loss intervention. The PSQ and the BRIEF were completed by each participant's caregiver. The BRIEF-SR and the PDSS were completed by the adolescents. The adolescents' height and weight were also recorded prior to intervention, and this data was used to calculate the participants' percent over BMI score and BMIz as described above. The Sleep-Related Breathing Disorder scale on the PSQ was used to assess the adolescents' risk of SDB. The 0.33 cutoff criterion as suggested by an ROC analysis in past research was used to determine the adolescents' risk of SDB (Chervin et al. 2000). We included those participants with a Sleep-Related Breathing Disorder scale on the PSQ of greater than 0.33 in the high-risk group and those with a score less than 0.33 in the minimal/low-risk group. This resulted in an average score of $0.56(\mathrm{SD}=0.14)$ in the highrisk group and an average of $0.25(\mathrm{SD}=0.08)$ in the low-risk group. After each participant completed the 12-week treatment program, they and their caregivers once again completed the BRIEF. Updated anthropometric data was collected at the 3 -month mark as well as at 1 year.

\section{Statistical Analyses}

SPSS 21 (IBM Corp., Armonk, New York) was used for most statistical analyses. STATA 13.1 (StataCorp. 2013, Stata Statistical Software: Release 13, College Station, TX: StataCorp LP.) was used for the Hotelling's $T^{2}$ analyses. Comparisons of categorical data were carried out using chisquare analyses, and comparisons of continuous data were made using $t$ tests. A Pearson correlation between the Global Executive Composite on the BRIEF and the PSQ was computed to evaluate the relationship between executive functioning and SDB. A Hotelling's $T^{2}$ was performed using the BRIEF-SR clinical scale $T$ scores as the dependent variables and SDB risk, as determined by the PSQ, as the fixed factor. A second Hotelling's $T^{2}$ was carried out using the BRIEF (parent-report) clinical scale $T$ scores as the dependent variables and SDB risk as the fixed factor. Finally, we calculated an effect size (Cohen's $d$ ) comparing Global Executive Composite scores between SDB risk and non-SDB risk groups. A regression analysis was undertaken to determine the stability of the relationship between SDB and executive function. The PSQ score at the time of intake was used as the independent variable, and the BRIEF Global Executive Composite was used as the dependent variable. Lastly, a path analysis model was used to determine whether executive functioning was a significant predictor of weight loss. The PSQ was used as a predictor of both the PDSS and the BRIEF Global Executive Composite, and the Global Executive Composite was also being predicted by the PDSS (this was included in the model in order to account for daytime sleepiness). Finally, the Global Executive Composite was used as a predictor of the total weight lost over a year. Due to the fact that the Global Executive Composite is made up of several executive domains, a post hoc analysis was conducted to determine if inhibitory control was associated with sleepdisordered breathing and weight loss. The same model described above was used, but the Inhibition Scale on the BRIEF replaced the Global Executive Composite. Inhibitory control was selected because this is the executive domain that has been most closely associated with weight control (Jasinska et al. 2012).

\section{Results}

Chi-square analyses revealed that there was not a significant difference in the proportion of males and females between the groups $\left(\chi^{2}(1, N=37)=0.95 ; p=0.33\right)$, proportion of 
participants reporting past diagnosis of ADHD $\left(\chi^{2}(1\right.$, $N=37)=1.8 ; p=0.18$ ), or proportion of participants with past diagnosis of a sleep disorder $\left(\chi^{2}(1, N=37)=0.79 ; p=0.37\right)$. Average age for the group at risk for SDB $(n=20)$ was 14.2 $(\mathrm{SD}=1.3)$, and the average age for the group at minimal risk $(n=17)$ was $14.4(\mathrm{SD}=1.7)$; there was no between group difference in age $(t(35)=.401, p=0.69)$. A $t$ test confirmed there was no between group differences in BMIz $(t(34)=0.102, p=0.92)$ or percent over BMI $(t(34)=30$, $p=.77)$. A Pearson correlation analysis demonstrated a strong association between the BRIEF Global Executive Composite and Sleep-Related Breathing Disorder scale on the PSQ $(r=0.75, p<0.001)$. Analyses showed that $53.7 \%$ of the total sample had a clinically significant $T$ score on the Global Executive Composite of the BRIEF parent form, while $77.3 \%$ of the adolescents in the at risk group and $27.8 \%$ of the adolescents in the minimal risk group had clinically significant $T$ scores on the same measure. The overall Hotelling's $T^{2}$ analysis examining associations between the BRIEF-SR and SDB risk did not demonstrate significant group differences in self-reported executive function between adolescents at risk for SDB and those at minimal risk. In contrast, the Hotelling's $T^{2}$ analysis comparing caregiver ratings of executive function between adolescents at risk for SDB and those at low or minimal risk was statistically significant (see Table 2).

This finding indicates that group differences in SDB risk account for a significant proportion of the pattern in parentreported executive functioning. All eight clinical scales were significantly different between groups and all three indices (i.e., Behavioral Regulation, Metacognition, Global Executive Composite) were significantly different between groups (see Table 3). The effect size of the difference between BRIEF Global Executive Composite scores between SDB risk groups demonstrated a large effect $(d=1.73)$. Means, standard deviations, $t$ statistics, and $p$ values for the clinical scales and indices for the BRIEF-SR and BRIEF by group (risk for SDB; low or high) are presented in Table 3 and Fig. 1.

The relationship between sleep-disordered breathing and executive functioning as measured by the Global Executive Composite appeared to be stable, and the Sleep-Related Breathing Disorder scale of the PSQ at intake predicted parent-reported executive functioning 3 months later $\left(\beta=0.54, t(13)=2.28, p=0.04, R^{2}=0.30\right)$. Results suggested that $30 \%$ of the variance in executive functioning at 3 months post-intake was explained by parent-reported symptoms of

Table 2 Results of the Hotelling's $T^{2}$ analyses for the BRIEF and BRIEF-SR, including the $T^{2}$ value and its associated $p$ value

\begin{tabular}{lll}
\hline & Hotelling's $T^{2}$ & $p$ value \\
\hline BRIEF parent-report & 57.47 & 0.003 \\
BRIEF self-report & 24.48 & 0.32 \\
\hline
\end{tabular}

SDB at intake. The results from the path analyses demonstrated that the PSQ was predictive of both the PDSS $(\beta=0.34$, $\left.\mathrm{SE}=0.14, p=0.018, R^{2}=.11\right)$ and the BRIEF Global Executive Composite $(\beta=0.70, \mathrm{SE}=0.08, p<.001)$. The PDSS was not a significant predictor of the Global Executive Composite $(\beta=0.14, \mathrm{SE}=0.11, p=0.21)$. The PDSS and the PSQ combined predicted $58 \%$ of the variance in the BRIEF Global Executive Composite $\left(R^{2}=0.58\right)$. However, the Global Executive Composite was not a significant predictor of weight loss $(\beta=0.22, \mathrm{SE}=0.36, p=.53$, $R^{2}=.05$ ). Post hoc analyses in which the Global Executive Composite was replaced by the Inhibition scale from the BRIEF demonstrated that the PSQ was predictive of both the PDSS $\left(\beta=0.34, \mathrm{SE}=0.14, p=0.018, R^{2}=0.11\right)$ and the BRIEF Inhibition scale $(\beta=0.46, \mathrm{SE}=0.12, p<0.001$, $\left.R^{2}=.11\right)$. The PDSS was not a significant predictor of the Inhibition subscale $(\beta=0.24, \mathrm{SE}=0.14, p=0.08)$; however, it approached statistical significance. The PDSS and the PSQ combined predicted $35 \%$ of the variance in the BRIEF Inhibition scale $\left(R^{2}=0.35\right)$. Finally, the BRIEF Inhibition scale was a significant predictor of weight loss and accounted for $28 \%$ of the variance in weight change $(\beta=-0.53$, $\mathrm{SE}=0.24, p=0.03, R^{2}=0.28$ ).

\section{Discussion}

Overweight and obese adolescents are at risk for SDB which in turn may have detrimental effects on executive functioning. About half of the overall sample exhibited clinically significant impairment in overall executive functioning as rated by their caregivers. Approximately three in four adolescents in the at risk group and about one in four in the minimal risk group exhibited similar impairments. These findings suggest that a large proportion of obese adolescents, and particularly those at risk for sleep-disordered breathing, may experience deficits in executive functioning. Thus, clinicians that are seeing adolescents that are obese may want to consider the possibility of SDB in the context of reported or observed executive dysfunction. In fact, it has been suggested that sleep disorders should be ruled out prior to diagnosis or treatment of ADHD (Hvolby 2015).

Findings from our study suggest that overweight/obese adolescents enrolled in a behavioral weight loss program who were at risk for SDB were rated by their caregiver as having significantly poorer executive functioning compared to adolescents at minimal risk for SDB. Between group differences in the Global Executive Composite, which represents overall executive function by combining all eight clinical scales from the BRIEF, demonstrated a very large effect size $(d=1.73)$. This finding suggests that caregivers of adolescents with SDB notice executive dysfunction in the adolescents' daily functioning. This finding may also suggest that the utilization of 
Table 3 Mean $T$ scores, (standard deviations), $t$ values, and $p$ values of the $t$ tests for the clinical scales, indices, and GEC for the BRIEF and BRIEF-SR

\begin{tabular}{|c|c|c|c|c|}
\hline & Low SDB risk & High SDB risk & $t$ & $p$ \\
\hline \multicolumn{5}{|l|}{ BRIEF parent-report } \\
\hline BRI & $55.71(7.83)$ & $66.65(10.91)$ & 3.45 & 0.0007 \\
\hline Inhibit & $52.41(9.68)$ & $63.25(13.50)$ & 2.76 & 0.005 \\
\hline Shift & $57.06(7.32)$ & $67.85(10.85)$ & 3.48 & 0.0007 \\
\hline Emotional control & $55.65(7.66)$ & $63.30(11.59)$ & 2.32 & 0.01 \\
\hline MI & $56.18(8.38)$ & $70.90(9.36)$ & 5.00 & 0.0000 \\
\hline Initiate & $58.24(7.80)$ & $73.40(8.77)$ & 5.52 & 0.0000 \\
\hline Working memory & $52.65(9.47)$ & $70.05(9.98)$ & 5.41 & 0.0000 \\
\hline Plan/organize & $55.06(8.92)$ & $66.15(10.06)$ & 3.52 & 0.0006 \\
\hline Organization of materials & $53.94(7.97)$ & $64.10(6.50)$ & 4.27 & 0.0001 \\
\hline Monitor & $55.71(8.48)$ & $66.35(8.22)$ & 3.87 & 0.0002 \\
\hline GEC & $56.06(7.64)$ & $70.65(9.21)$ & 5.19 & 0.0000 \\
\hline \multicolumn{5}{|l|}{ BRIEF self-report } \\
\hline BRI & $53.94(13.32)$ & $57.45(11.16)$ & 0.87 & 0.19 \\
\hline Inhibit & $52.18(11.13)$ & $54.45(9.30)$ & 0.68 & 0.25 \\
\hline Shift & $52.71(14.04)$ & $59.10(10.52)$ & 1.58 & 0.06 \\
\hline Behavioral shift & $51.59(12.07)$ & $54.15(9.43)$ & 0.73 & 0.24 \\
\hline Cognitive shift & $53.06(15.36)$ & $61.85(11.47)$ & 1.99 & 0.03 \\
\hline Emotional control & $54.65(12.04)$ & $55.85(15.26)$ & 0.26 & 0.40 \\
\hline Monitor & $52.88(12.67)$ & $54.90(7.31)$ & 0.60 & 0.27 \\
\hline MI & $56.41(17.55)$ & $62.15(12.50)$ & 1.16 & 0.13 \\
\hline Working memory & $57.24(17.83)$ & $60.40(12.51)$ & 0.63 & 0.27 \\
\hline Plan/organize & $54.71(14.43)$ & $59.35(11.82)$ & 1.08 & 0.15 \\
\hline Organization of materials & $51.35(17.17)$ & $57.80(11.78)$ & 1.35 & 0.09 \\
\hline Task completion & $54.00(17.26)$ & $63.50(12.43)$ & 1.94 & 0.03 \\
\hline GEC & $55.65(16.58)$ & $60.80(12.24)$ & 1.09 & 0.14 \\
\hline
\end{tabular}

$S D B$ sleep-disordered breathing, BRIEF Behavior Rating Inventory of Executive Function, BRI Behavioral Regulation Index, $M I$ Metacognition Index, GEC Global Executive Composite the PSQ in conjunction with the BRIEF may be highly effective screening tools in determining executive dysfunction in the presence of possible SDB. These effects are larger than have been observed in previous studies using self-report or objective measures (O'Brien et al. 2004; Tan et al. 2014). In contrast to group differences based on parent-report, there were no group differences in self-reported executive function between adolescents at risk for SDB compared to those at minimal risk. The reason underlying differences between parent and self-report in regards to executive function in this sample was unclear. However, similar findings have been reported in adolescents following traumatic brain injury in that one study noted that parents reported significantly greater executive dysfunction than their child, using the BRIEF. The authors attributed this finding to a lack of deficit awareness (Wilson et al. 2011). Thus, our findings suggest that adolescents at risk for SDB may also have limited insight into deficits related to executive function.

We would point out that many of the subscales and indices from the BRIEF parent-report form that were elevated in the
SDB at risk group would be considered to be in the clinically significant range (see Table 3). More specifically, adolescents at risk for SDB were rated as having deficits in working memory, as well as the ability to plan and organize. Other reported deficits include abilities related to transitioning efficiently from one activity to another and making careless mistakes or failing to check their work. Broadly speaking, their abilities to control their emotions and behavior appropriate to the environment and to use appropriate problem-solving abilities were rated to be in the impaired range. It is important to note that there were no significant group differences in past diagnoses of ADHD between adolescents at risk for SDB and those not at risk. Demonstrating that the executive deficits noted are not due to ADHD is important because past research has shown that children with SDB are at increased risk for ADHD (Chervin et al. 2002). However, the patterns of our results are similar to those reported by Toplak et al. (2009) in adolescents with ADHD who had elevated scores on the inhibit, shift, working memory, and plan/organize subscales of the BRIEF. Similarly, adolescents with ADHD have demonstrated deficits in their abilities to plan 
Fig. 1 A profile of the clinical scales of the BRIEF and the BRIEF-SR for those at risk for SDB and those not at risk for SDB

\section{BRIEF AND BRIEF-SR CLINICAL SCALES}

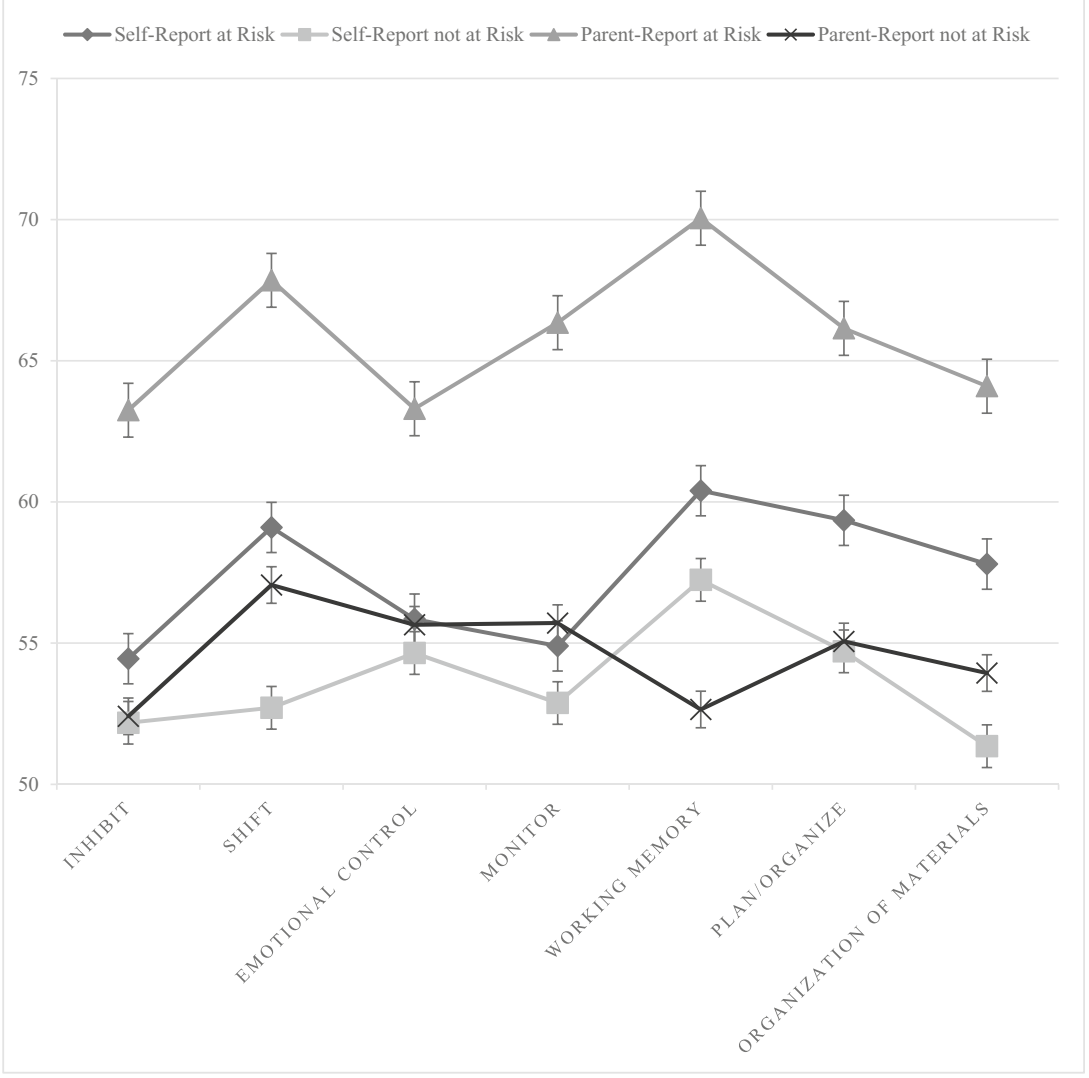

and organize, control their emotions and behavior, and utilize optimal problem-solving strategies. This similarity is striking and likely reflects an overlap in behavioral presentation between SDB and ADHD. For example, increased inattention and hyperactivity have been associated with increased SDB severity in children and adolescents (Chervin et al. 2002). In addition, SDB symptoms, specifically snoring, is a predictor of hyperactivity (Chervin et al. 2005). Importantly, treatment for SDB has been associated with remission of symptoms of inattention and hyperactivity lending evidence to the notion that SDB may be playing an important role in generating symptoms of inattention, hyperactivity, and executive dysfunction (Ali et al. 1996).

These findings also suggest that SDB has negative effects on executive function abilities that cannot be explained by daytime sleepiness alone. While SDB seems to affect executive functioning more broadly, these broad executive abilities in our sample did not necessarily seem to affect weight change. However, when examining caregiver-reported inhibitory control, our findings suggested that SDB was predictive of inhibitory control, and inhibitory control was then predictive of weight change over a 1-year period. Thus, our findings may have important clinical implications for obese adolescents participating in a behavioral weight loss program because we found a high incidence of children that may be at risk for SDB and that these children tended to be rated as having executive dysfunction by their caregivers and ratings of poor inhibitory control were predictive of weight change over 1 year.

Clinical impairment in executive function may make it more difficult for obese adolescents to reach weight loss goals. McNally et al. (2010) demonstrated that children with deficits in executive function displayed poorer adherence to treatment of diabetes. In their study, strict treatment adherence predicted more favorable outcomes and level of executive functioning was related to treatment adherence. It has also been demonstrated that individuals with ADHD and executive functioning deficits struggle to be successful in weight loss interventions (Cortese et al. 2013). Relatedly, executive dysfunction has been associated with increased body mass (Gunstad et al. 2007), suggesting that executive functioning is important in the maintenance of a healthy weight. Finally, the importance of the association between executive functioning and weight loss has been demonstrated in a prior study. Children in a weight loss program that received training (in the form of a game) to improve executive functioning not only showed marked improvement on tasks of working memory as well as measures of working 
memory and meta-cognition as measured by the BRIEF but were also more successful at maintaining their weight loss 8 weeks post-intervention (Verbeken et al. 2013). Taken together with our current findings, adolescents with SDB and executive dysfunction may have more difficulty adhering to treatment recommendations and thus achieving identified weight loss goals. Therefore, screening for SDB and gauging a child's executive functioning may be important in weight loss treatment planning. Future research should be conducted to determine if SDB affects an adolescent's success in weight loss intervention programs and how treatment for SDB may modify this association.

\section{Limitations}

This study had several limitations. First, our study utilized cross-sectional data and we cannot make causal statements. Second, the measures of executive function were limited to self-report and parent-report measures without direct assessment of executive function and our findings may underestimate or overestimate executive dysfunction. Thus, future studies will need to incorporate objective measures of executive function to compare to the self and parent-report measures. However, a study by Beebe et al. (2004) demonstrated that not only was the BRIEF sensitive to executive impairments in children with SDB (ranging from mild snoring to OSA) but that these same children who displayed impairment on BRIEF subscales also showed impairment on objective neuropsychological measures including measures of verbal fluency, sustained attention, and processing speed. Third, despite adequate validity and reliability of the PSQ in identifying increased risk of SDB, the participants in this study did not undergo polysomnography which precludes confirmation of SDB using physiological assessment. Still, the current data represents preliminary work supporting the link between obesity and increased risk of SDB and that adolescents with higher risk of SDB tended to be rated as having executive impairment which was also associated with weight loss. Another limitation is the unavailability of follow-up measures of executive function and SDB risk after completion of the weight loss program. Finally, a recent paper suggested that working memory performance in overweight and obese adolescents may be mediated by changes in cerebral white matter (Alarcon et al. 2015). Thus, it is possible that performance on the BRIEF, which includes a subscale related to observations of working memory, may have been affected by cerebral changes attributed to increased body mass rather than SDB. However, we would note that if impairment on the BRIEF were exclusively related to weight, then there would not have been such a large group difference between those at high or minimal risk for SDB and that the non-risk group should also have had clinically elevated BRIEF scores (which they did not). Still, given that the magnitude of the effect size we found and that it was much larger than prior studies limited to executive function and SDB, consideration of the possibility of an interaction between obesity and SDB may be warranted. Future studies may want to address this issue.

\section{Conclusions}

Obesity is a risk factor for sleep-disordered breathing which has been associated with various health problems and cognitive dysfunction. We found that a substantial proportion of the overweight/obese adolescents in a behavioral weight loss program had symptoms suggestive of sleep-disordered breathing and that those at risk for SDB were rated by their caregivers as having impairment in various aspects of executive function. In contrast, self-ratings in those adolescents at risk for sleepdisordered breathing were not different from those adolescents not at risk. Thus, it is possible that the adolescents rated as having executive impairment by their caregivers may have demonstrated impaired insight into their executive function. We also demonstrated SDB may have negative effects on inhibitory control, and parent-reported inhibitory control was predicative of weight change over time. Given the importance of executive function in achieving weight loss goals coupled with our findings, we suggest that future studies evaluating the efficacy of weight loss interventions in obese and overweight adolescents consider screening participants for sleepdisordered breathing. Finally, the current findings suggest that clinicians assessing adolescents for cognitive function may want to consider the possible contributing factors of SDB.

Compliance with Ethical Standards All procedures performed in this study were in accordance with the ethical standards of Brigham Young University, approved by the IRB, and with the 1964 Helsinki declaration and its later amendments or comparable ethical standards.

Conflict of Interest We report no conflict of interest for any author.

Informed Consent Informed consent was obtained from all individual participants included in this study.

Funding This study was not grant funded.

\section{References}

Alarcon, G., Ray, S., \& Nagel, B. J. (2015). Lower working memory performance in overweight and obese adolescents is mediated by white matter microstructure. Journal of International Neuropsychological Society, 22(3), 281-92. doi:10.1017 /S1355617715001265.

Ali, N. J., Pitson, D., \& Stradling, J. R. (1996). Sleep disordered breathing: effects of adenotonsillectomy on behaviour and psychological functioning. European Journal of Pediatrics, 155(1), 56-62.

Alonso-Alvarez, M. L., Cordero-Guevara, J. A., Teran-Santos, J., Gonzalez-Martinez, M., Jurado-Luque, M. J., Corral-Penafiel, J., 
\& Gozal, D. (2014). Obstructive sleep apnea in obese communitydwelling children: the NANOS study. Sleep, 37(5), 943-949.

Bass, J. L., Corwin, M., Gozal, D., Moore, C., Nishida, H., Parker, S., \& Kinane, T. B. (2004). The effect of chronic or intermittent hypoxia on cognition in childhood: a review of the evidence. Pediatrics, 114(3), 805-816. doi:10.1542/peds.2004-0227.

Beebe, D. W., \& Gozal, D. (2002). Obstructive sleep apnea and the prefrontal cortex: towards a comprehensive model linking nocturnal upper airway obstruction to daytime cognitive and behavioral deficits. Journal of Sleep Research, 11(1), 1-16.

Beebe, D. W., Wells, C. T., Jeffries, J., Chini, B., Kalra, M., \& Amin, R. (2004). Neuropsychological effects of pediatric obstructive sleep apnea. Journal of International Neuropsychological Society, 10(7), 962-975.

Berman, K. F., Ostrem, J. L., Randolph, C., Gold, J., Goldberg, T. E., Coppola, R., \& Weinberger, D. R. (1995). Physiological activation of a cortical network during performance of the Wisconsin Card Sorting Test: a positron emission tomography study. Neuropsychologia, 33(8), 1027-1046.

Bourke, R., Anderson, V., Yang, J. S., Jackman, A. R., Killedar, A., Nixon, G. M., \& Horne, R. S. (2011). Cognitive and academic functions are impaired in children with all severities of sleepdisordered breathing. Sleep Medicine, 12(5), 489-496. doi:10.1016/j.sleep.2010.11.010.

Centers for Disease Control and Prevention. (n.d.). US department of health and human services, division of nutrition, physical activity, and obesity, national center for chronic disease prevention and health promotion. A SAS program for the CDC growth charts. Retrieved from http://www.cdc.gov/nccdphp/dnpao/growthcharts/resources/sas.htm. Accessed 1 Mar, 2016.

Chervin, R. D., Hedger, K., Dillon, J. E., \& Pituch, K. J. (2000). Pediatric sleep questionnaire (PSQ): validity and reliability of scales for sleepdisordered breathing, snoring, sleepiness, and behavioral problems. Sleep Medicine, 1(1), 21-32.

Chervin, R. D., Archbold, K. H., Dillon, J. E., Panahi, P., Pituch, K. J., Dahl, R. E., \& Guilleminault, C. (2002). Inattention, hyperactivity, and symptoms of sleep-disordered breathing. Pediatrics, 109(3), 449-456.

Chervin, R. D., Ruzicka, D. L., Archbold, K. H., \& Dillon, J. E. (2005). Snoring predicts hyperactivity four years later. Sleep, 28(7), 885890.

Cortese, S., Comencini, E., Vincenzi, B., Speranza, M., \& Angriman, M. (2013). Attention-deficit/hyperactivity disorder and impairment in executive functions: a barrier to weight loss in individuals with obesity? BMC Psychiatry, 13, 286. doi:10.1186/1471-244X-13-286.

Drake, C., Nickel, C., Burduvali, E., Roth, T., Jefferson, C., \& Pietro, B. (2003). The pediatric daytime sleepiness scale (PDSS): sleep habits and school outcomes in middle-school children. Sleep, 26(4), 455458 .

Engleman, H. M., Cheshire, K. E., Deary, I. J., \& Douglas, N. J. (1993). Daytime sleepiness, cognitive performance and mood after continuous positive airway pressure for the sleep apnoea/hypopnoea syndrome. Thorax, 48(9), 911-914.

Engleman, H. M., Martin, S. E., Deary, I. J., \& Douglas, N. J. (1997). Effect of CPAP therapy on daytime function in patients with mild sleep apnoea/hypopnoea syndrome. Thorax, 52(2), 114-119.

Gioia, G. A., Isquith, P. K., Guy, S. C., \& Kenworthy, L. (2000). Behavior rating inventory of executive function professional manual. Lutz: Psychological Assessment Resources.

Goldman, R. L., Canterberry, M., Borckardt, J. J., Madan, A., Byrne, T. K., George, M. S., \& Hanlon, C. A. (2013). Executive control circuitry differentiates degree of success in weight loss following gastric-bypass surgery. Obesity (Silver Spring), 21(11), 21892196. doi:10.1002/oby.20575.

Gunstad, J., Paul, R. H., Cohen, R. A., Tate, D. F., Spitznagel, M. B., \& Gordon, E. (2007). Elevated body mass index is associated with executive dysfunction in otherwise healthy adults. Comprehensive Psychiatry, 48(1), 57-61. doi:10.1016/j.comppsych.2006.05.001.

Hunter, Scott J, Gozal, David, Smith, Dale L, Philby, Mona F, Kaylegian, Jaeson, \& Kheirandish-Gozal, Leila. (2016). Effect of sleepdisordered breathing severity on cognitive performance measures in a large community cohort of young school-aged children. American journal of respiratory and critical care medicine(ja) [Epub ahead of print]

Hvolby, A. (2015). Associations of sleep disturbance with ADHD: implications for treatment. Adhd-Attention Deficit and Hyperactivity Disorders, 7(1), 1-18. doi:10.1007/s12402-014-0151-0.

Jasinska, A. J., Yasuda, M., Burant, C. F., Gregor, N., Khatri, S., Sweet, M., \& Falk, E. B. (2012). Impulsivity and inhibitory control deficits are associated with unhealthy eating in young adults. Appetite, 59(3), 738-747. doi:10.1016/j.appet.2012.08.001.

Jones, K., \& Harrison, Y. (2001). Frontal lobe function, sleep loss and fragmented sleep. Sleep Medicine Reviews, 5(6), 463-475. doi:10.1053/smrv.2001.0203.

Karpinski, A. C., Scullin, M. H., \& Montgomery-Downs, H. E. (2008). Risk for sleep-disordered breathing and executive function in preschoolers. Sleep Medicine, 9(4), 418-424. doi:10.1016/j. sleep.2007.06.004.

Kuczmarski, Robert J, Ogden, Cynthia L, Guo, Shumei S, GrummerStrawn, Laurence M, Flegal, Katherine M, Mei, Zuguo,....Johnson, Clifford L. (2002). 2000 CDC growth charts for the United States: methods and development. Vital and Health Statistics. Data from the National Health Survey 11(246), 1-190.

Lobstein, T., Baur, L., \& Uauy, R. (2004). Obesity in children and young people: a crisis in public health. Obesity Reviews, 5(Suppl 1), 4-104. doi:10.1111/j.1467-789X.2004.00133.x.

McNally, K., Rohan, J., Pendley, J. S., Delamater, A., \& Drotar, D. (2010). Executive functioning, treatment adherence, and glycemic control in children with type 1 diabetes. Diabetes Care, 33(6), 1159 1162. doi: $10.2337 / \mathrm{dc} 09-2116$

McNally, K., Shear, P. K., Tlustos, S., Amin, R. S., \& Beebe, D. W. (2012). Iowa gambling task performance in overweight children and adolescents at risk for obstructive sleep apnea. Journal of International Neuropsychological Society, 18(3), 481-489. doi:10.1017/S1355617711001937.

Montesano, M., Miano, S., Paolino, M. C., Massolo, A. C., Ianniello, F., Forlani, M., \& Villa, M. P. (2010). Autonomic cardiovascular tests in children with obstructive sleep apnea syndrome. Sleep, 33(10), 1349-1355.

Nisbet, L. C., Yiallourou, S. R., Biggs, S. N., Nixon, G. M., Davey, M. J., Trinder, J. A., \& Horne, R. S. (2013). Preschool children with obstructive sleep apnea: the beginnings of elevated blood pressure? Sleep, 36(8), 1219-1226. doi:10.5665/sleep.2890.

O'Brien, L. M., Mervis, C. B., Holbrook, C. R., Bruner, J. L., Smith, N. H., McNally, N., \& Gozal, D. (2004). Neurobehavioral correlates of sleep-disordered breathing in children. Journal of Sleep Research, 13(2), 165-172. doi:10.1111/j.1365-2869.2004.00395.x.

Ogden, C. L., Carroll, M. D., Kit, B. K., \& Flegal, K. M. (2014). Prevalence of childhood and adult obesity in the United States, 2011-2012. JAMA, 311(8), 806-814. doi:10.1001/jama.2014.732.

Paluch, R. A., Epstein, L. H., \& Roemmich, J. N. (2007). Comparison of methods to evaluate changes in relative body mass index in pediatric weight control. American Journal of Human Biology, 19(4), 487494. doi:10.1002/ajhb.20608.

Pietropaoli, N., Supino, M. C., Vitelli, O., Rabasco, J., Evangelisti, M., Forlani, M., \& Villa, M. P. (2015). Cognitive function in preschool children with sleep-disordered breathing. Sleep and Breathing, 19(4), 1431-1437.

Pretlow, R. A., Stock, C. M., Allison, S., \& Roeger, L. (2015). Treatment of child/adolescent obesity using the addiction model: a smartphone app pilot study. Child Obesity, 11(3), 248-259. doi:10.1089 /chi.2014.0124. 
Redline, S., Tishler, P. V., Schluchter, M., Aylor, J., Clark, K., \& Graham, G. (1999). Risk factors for sleep-disordered breathing in children. Associations with obesity, race, and respiratory problems. American Journal of Respiratory and Critical Care Medicine, $159(5 \mathrm{Pt} 1)$, 1527-1532. doi:10.1164/ajrccm.159.5.9809079.

Redline, S., Storfer-Isser, A., Rosen, C. L., Johnson, N. L., Kirchner, H. L., Emancipator, J., \& Kibler, A. M. (2007). Association between metabolic syndrome and sleep-disordered breathing in adolescents. American Journal of Respiratory and Critical Care Medicine, 176(4), 401-408. doi:10.1164/rccm.200703-375OC.

Tan, E., Healey, D., Schaughency, E., Dawes, P., \& Galland, B. (2014). Neurobehavioural correlates in older children and adolescents with obesity and obstructive sleep apnoea. Journal of Paediatrics and Child Health, 50(1), 16-23. doi:10.1111/jpc.12390.

Thomas, R. J., Rosen, B. R., Stern, C. E., Weiss, J. W., \& Kwong, K. K. (2005). Functional imaging of working memory in obstructive sleep-disordered breathing. Journal of Applied Physiology (1985), 98(6), 2226-2234. doi:10.1152/japplphysiol.01225.2004.

Toplak, M. E., Bucciarelli, S. M., Jain, U., \& Tannock, R. (2009). Executive functions: performance-based measures and the behavior rating inventory of executive function (BRIEF) in adolescents with attention deficit/hyperactivity disorder (ADHD). Child Neuropsychology, 15(1), 53-72. doi:10.1080/09297040802070929.

Verbeken, S., Braet, C., Goossens, L., \& van der Oord, S. (2013). Executive function training with game elements for obese children: a novel treatment to enhance self-regulatory abilities for weightcontrol. Behaviour Research and Therapy, 51(6), 290-299. doi:10.1016/j.brat.2013.02.006.

Verhulst, S. L., Van Gaal, L., De Backer, W., \& Desager, K. (2008). The prevalence, anatomical correlates and treatment of sleep-disordered breathing in obese children and adolescents. Sleep Medicine Reviews, 12(5), 339-346. doi:10.1016/j.smrv.2007.11.002.

Walker, J. M., \& D'Amato, R. (2006). Review of 'Behavior Rating Inventory of Executive Function-Self-Report version'. Journal of Psychoeducational Assessment, 24(4), 394-398. doi:10.1177 /0734282906288390.

Wilson, K. R., Donders, J., \& Nguyen, L. (2011). Self and parent ratings of executive functioning after adolescent traumatic brain injury. Rehabilitation Psychology, 56(2), 100-106. doi:10.1037 /A0023446. 